\title{
An Extended Kalman Filter Approach to Rotor Time Constant Measurement in PWM Induction Motor Drives
}

\author{
Li-Cheng Zai, Member, IEEE, Christopher L. DeMarco, Member, IEEE, and Thomas A. Lipo, \\ Fellow, IEEE
}

\begin{abstract}
A rotor time constant estimation technique for the purpose of updating the control gains of an induction motor field-oriented controller is described. An extended Kalman filter is employed to estimate the inverse rotor time constant on line only using measurements of the stator voltages and currents and rotor speed of an induction motor. The motor is driven by a pulse-width modulated (PWM) inverter with or without current feedback loops. By utilizing the wide-band harmonic contents inherent in conventional PWM voltage waveforms, no external random test signal is required for parameter estimation. Both computer simulation and experimental results demonstrate that the filter is capable of estimating the rotor time constant while the rotor speed is either constant or time varying.
\end{abstract}

\section{INTRODUCTION}

F ELD-ORIENTED techniques utilizing microprocessors are now widely used for the control of induction motor drives in high-performance applications. Two generic types of field-oriented control are available to regulate the rotor flux. The direct flux control scheme senses the air-gap flux by use of the Hall effect sensor, search coil, or other measurement techniques [1]. The measured flux is then fed back to a controller, enabling the rotor flux to be regulated. This method is considered to be expensive because special modifications on the motor are required. The indirect flux control method regulates the flux indirectly by using the rotor speed and setting the slip frequency as a function of the stator currents [2]. The indirect scheme, by virtue of its simpler sensing technique, is the favored method in the industry today. However, its performance strongly depends on the motor parameters, particularly the rotor time constant.

Recent work [3], [4] on the influence of motor parameter deviations on indirect field-oriented control systems indicates that error in the rotor time constant results in steady-state errors in torque and flux. In addition, the transient torque exhibits an oscillatory response and cannot follow rapid changes in the torque command. Numerous methods [5]-[10] have been proposed to circumvent this problem. However,

Paper IPCSD, approved by the Industrial Drives Committee of the IEEE Industry Applications Society for presentation at the 1987 Industry Applications Society Annual Meeting, Atlanta, GA, October 18-23. Manuscript released for publication April 15, 1991.

L.-C. Zai is with IBM Research Laboratories, Yorktown Heights, NY 10598

C. L. DeMarco and T. A. Lipo are with the Department of Electrical and Computer Engineering, University of Wisconsin, Madison, WI 53706-1691. IEEE Log Number 9103731. all of these methods identify the rotor time constant by injecting test signals, which disturb the normal operating functions of the drive, into the motor. In general, the fieldoriented control principle can be applied without regard to the type of inverter. The recent activity in the development of high-power bipolar and MOSFET transistors has made the current-regulated pulse-width modulated (CRPWM) inverter the popular choice in fast response ac servo applications [11], [12]. This approach employs a fast-switching PWM inverter to control the currents supplied to the motor on an almost instantaneous basis.

Methods combining state and parameter estimation with an extended Kalman filter were proposed before [13], [14], but both methods were verified only by computer simulation, and neither addressed the issues related to the PWM drive widely used in the motor industry. The accuracy of the estimation is heavily dependent on the stator voltage and magnetizing inductance used in the filter algorithm. These were treated as known parameters in the computer simulations of [13], [14]; in practice, they are not easy to obtain.

In this paper, retrieval of fundamental components of the stator voltage and on-line calculation of the magnetizing inductance are discussed. Moreover, the filter algorithm is arranged in a form that is suitable for microprocessor implementation by selecting the currents of stator and rotor and inverse rotor time constant as state variables. The advantage of using stator currents as the state variables is that they are directly measurable. It is demonstrated that the voltage waveform of the PWM inverter has a broad-band spectrum. This wideband harmonic spectrum can be considered as a noise input that is impressed on the motor by the inverter itself. Hence, a random input for parameter identification is inherently available, and no external test signals are required for the machine parameter estimation. When the motor speed changes, the machine model becomes, in effect, a two input/two output time-varying system with a superimposed noise input. The extended Kalman filter approach is ideally suited for parameter estimation of such a system and is demonstrated to be a viable, computationally efficient candidate for on-line estimation of the rotor time constant.

Influence of Rotor Time Constant Change on Indirect Field-Oriented Control Performance

The principle of field orientation is thoroughly presented in [12]. The dynamic behavior of a three-phase and three-wire 
induction machine with a squirrel-cage rotor can be described in a $d-q$ rotation reference frame. With proper constraints, the $d-q$ frame can be made to rotate synchronously with the stator or rotor flux. The so-called fieldoriented control allows the rotor flux to be perfectly aligned with the $d$ axis of the $d-q$ frame.

With a CRPWM inverter, the output currents and the frequency are the regulated variables. Indirect field-oriented control can be considered as a special means for controling the stator currents and slip frequency of an induction machine. By properly selecting the command stator currents $i_{q s}^{e^{*}}$ and $i_{d s}^{\mathrm{e}^{*}}$ and slip angular frequency $\omega_{s}$, i.e.

$$
\omega_{s}=\frac{r_{r}}{L_{r}} \frac{L_{m} i_{q s}^{e}}{\lambda_{d r}^{e}}
$$

the rotor flux can be placed in the $d$ axis. The rotor flux linkage $\lambda_{d r}^{e}$ in (1) is governed by

$$
\left(1+\frac{L_{r}}{r_{r}} p\right) \lambda_{d r}^{e}=L_{m} i_{d s}^{e}
$$

where $p=d / d t$. Equation (2) implies that in the steady state

$$
\lambda_{d r}^{e}=L_{m} i_{d s}^{e} \quad \text { (steady state) } .
$$

The output torque of the motor is

$$
T=\frac{3}{2} \frac{P}{2}\left(\frac{L_{m}}{L_{r}}\right) \lambda_{d r}^{e} i_{q s}^{e}
$$

In the above equations, the $i_{q s}^{e}, i_{d s}^{e}, \lambda_{d r}^{e}$, and $\lambda_{q r}^{e}$ are defined in the synchronous reference frame. The torque and flux can thus be independently controlled by $i_{q s}^{e}$ and $i_{d s}^{e}$, respectively. Since the stator currents to the CRPWM inverter are preselected, the necessary stator frequency can be obtained by simply summing the command slip frequency with the measured rotor frequency (i.e., speed)

$$
\omega_{e}^{*}=\omega_{r}+\omega_{s}^{*} .
$$

For an indirect field-orientated controller, the command slip frequency $\omega_{s}^{*}$ is determined by substituting a nominal inverse rotor time constant $\left(r_{r} / L_{r}\right)^{*}$ in (1), and the slip angular frequency command $\omega_{s}$ becomes

$$
\omega_{s}^{*}=\left(\frac{r_{r}}{L_{r}}\right)^{*} \frac{L_{m} i_{q s}^{e^{*}}}{\lambda_{d r}^{e^{*}}}
$$

Asterisks are used to denote the command or input quantities. If the value of inverse rotor time constant used in the (6) deviates from the real value, decoupling control of the flux and the torque will be lost. Accordingly, the steady-state and the transient responses of the indirect field-orientated drive system will be degraded. This phenomenon is referred to as "detuning" of the controller. In the steady state, detuning can result in the machine being either overexcited or underexcited. Overexciting a machine can cause it to saturate and thus increase the losses of the machine. On the other hand, the machine is not being effectively used if it is underexcited.

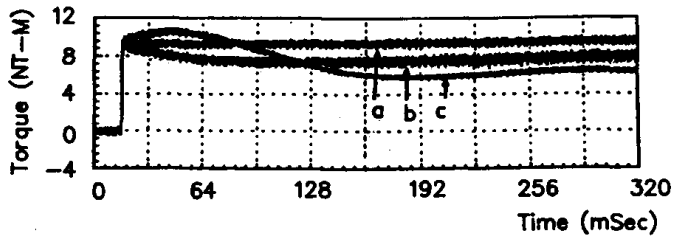

Fig. 1. Torque response of a 3-hp induction machine driven by a CRPWM inverter with indirect field-oriented control: (a) $\left(r_{r} / L_{r}\right)^{*}=r_{r} / L_{r} ;$ (b) $\left(r_{r} / L_{r}\right)^{*}=0.5 r_{r} / L_{r} ;(\mathrm{c})\left(r_{r} / L_{r}\right)^{*}=1.5 r_{r} / L_{r}$.

Furthermore, the transient output torque of the machine exhibits an oscillatory response and cannot follow a step change in the input torque command. Computer simulation of the detuning effects due to variations of the inverse rotor time constant is shown in Fig. 1.

\section{Formulation of Extended Kalman Filter for Estimating INVERSE Rotor TIME CONSTANT $\frac{r_{r}}{L_{r}}$.}

For simplicity, all the variables in the following parts of this paper are defined in the stationary reference frame. The electric dynamics of an induction motor in a stationary reference frame can be described as [10]

$$
\begin{aligned}
{\left[\begin{array}{c}
v_{q s} \\
v_{d s} \\
0 \\
0
\end{array}\right]=} & {\left[\begin{array}{cccc}
r_{s}+L_{s} p & 0 & L_{m} p & 0 \\
0 & r_{s}+L_{s} p & 0 & L_{m} p \\
L_{m} p & -\omega L_{m} & r_{r}+L_{r} p & -\omega_{r} L_{r} \\
\omega_{r} L_{m} & L_{m} p & \omega_{r} L_{r} & r_{r}+L_{r} p
\end{array}\right] } \\
& \cdot\left[\begin{array}{c}
i_{q s} \\
i_{d s} \\
i_{q r} \\
i_{d r}
\end{array}\right] .
\end{aligned}
$$

The extended Kalman filter algorithm [15] is summarized in Appendix A. To apply the filter algorithm, the dynamic model of the motor in a stationary reference frame is expressed in a vector set of differential equations. The state variables are selected as

$$
\begin{aligned}
{\left[\begin{array}{lllll}
x_{1} & x_{2} & x_{3} & x_{4} & x_{5}
\end{array}\right]^{T} } \\
=\left[\begin{array}{lllll}
i_{q s} & i_{d s} & i_{q r} & i_{d r} & \frac{r_{r}}{L_{r}}
\end{array}\right]^{T} .
\end{aligned}
$$

The spectrum of a typical PWM voltage, shown in Fig. 2, indicates the presence of a fundamental component along with wideband harmonics.

Treating the fundamental component as the deterministic input $u(t)$ and all the wideband harmonics as white Gaussian noise $w(t)$, the dynamic behavior of a three-phase induction machine is modeled as

$$
\dot{x}(t)=f[x(t), u(t), t]+G(t) w(t)
$$




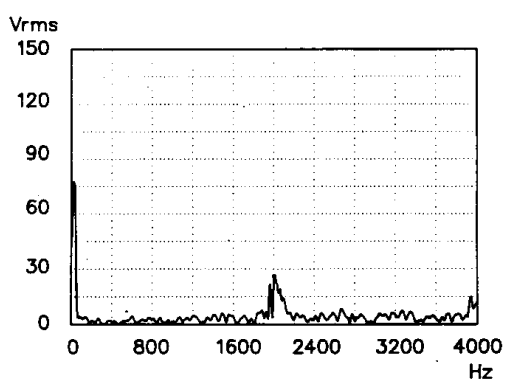

Fig. 2. Experimental voltage spectrum of a CRPWM inverter.

where

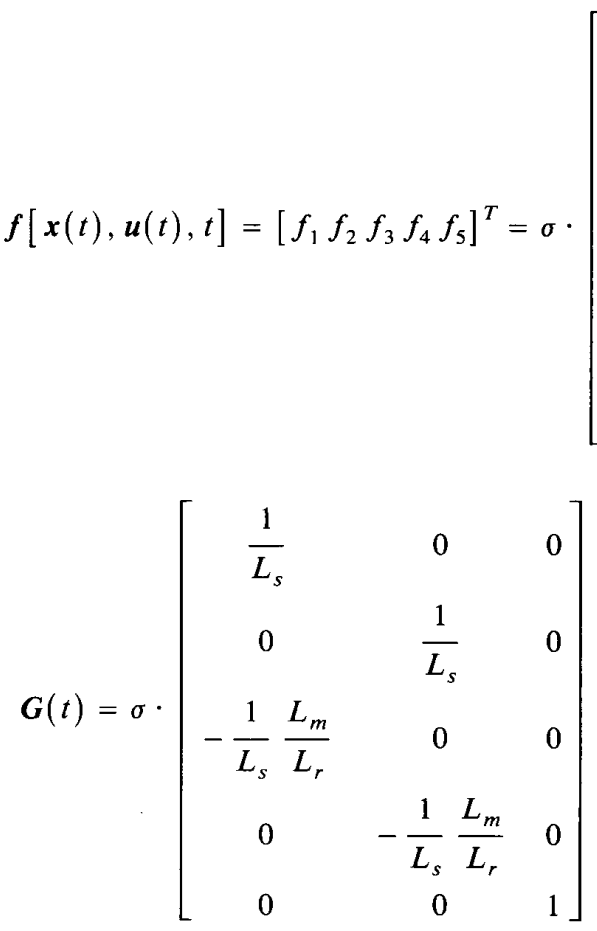

$$
\begin{aligned}
& w(t)=\left[\begin{array}{c}
w_{1}(t) \\
w_{2}(t) \\
n(t)
\end{array}\right] \\
& \sigma=\frac{L_{s} L_{r}}{L_{s} L_{r}-L_{m}^{2}} \text {. }
\end{aligned}
$$

$$
\left.\begin{array}{c}
-\frac{r_{s}}{L_{s}} x_{1}-\frac{L_{m}^{2}}{L_{s} L_{r}} \omega_{r} x_{2}+\frac{L_{m}}{L_{s}} x_{3} x_{5}-\frac{L_{m}}{L_{s}} \omega_{r} x_{4}+\frac{1}{L_{s}} v_{q s f} \\
\frac{L_{m}^{2}}{L_{s} L_{r}} \omega_{r} x_{1}-\frac{r_{s}}{L_{s}} x_{2}+\frac{L_{m}}{L_{s}} \omega_{r} x_{3}+\frac{L_{m}}{L_{s}} x_{4} x_{5}+\frac{1}{L_{s}} v_{d s f} \\
\frac{L_{m}}{L_{r}} \frac{r_{s}}{L_{s}} x_{1}+\frac{L_{m}}{L_{r}} \omega_{r} x_{2}-x_{3} x_{5}+\omega_{r} x_{4}-\frac{1}{L_{s}} \frac{L_{m}}{L_{r}} v_{q s f} \\
-\frac{L_{m}}{L_{r}} \omega_{r} x_{1}+\frac{L_{m}}{L_{r}} \frac{r_{s}}{L_{s}} x_{2}-\omega_{r} x_{3}-x_{4} x_{5}-\frac{1}{L_{s}} \frac{L_{m}}{L_{r}} v_{d s f}
\end{array}\right]
$$

$$
v\left(t_{i}\right)=\left[\begin{array}{l}
i_{q s h}\left(t_{i}\right) \\
i_{d s h}\left(t_{i}\right)
\end{array}\right]
$$

where $v\left(t_{i}\right)$ is the measurement noise vector that includes the wideband harmonics in the motor currents and the measurement noise of current sensors. $i_{q s f}$ and $i_{d s f}$ are the fundamental components of the stator current waveforms. From (10) and (13), the matrices $\boldsymbol{F}$ and $\boldsymbol{H}$ can be defined as

$$
\begin{aligned}
& \boldsymbol{F}[\boldsymbol{x}(t), t]=\left.\frac{\partial f[\boldsymbol{x}(t), \boldsymbol{u}(t), t]}{\partial \boldsymbol{x}}\right|_{x=\hat{x}(t)}= \\
& \sigma \cdot\left[\begin{array}{ccccc}
-\frac{r_{s}}{L_{s}} & \frac{-L_{m}^{2}}{L_{s} L_{r}} \omega_{r} & \frac{L_{m}}{L_{s}} x_{5} & -\frac{L_{m}}{L_{s}} \omega_{r} & \frac{L_{m}}{L_{s}} x_{3} \\
\frac{L_{m}^{2}}{L_{s} L_{r}} \omega_{r} & -\frac{r_{s}}{L_{s}} & \frac{L_{m}}{L_{s}} \omega_{r} & \frac{L_{m}}{L_{s}} x_{5} & \frac{L_{m}}{L_{s}} x_{4} \\
\frac{L_{m}}{L_{r}} \frac{r_{s}}{L_{s}} & \frac{L_{m}}{L_{r}} \omega_{r} & -x_{5} & \omega_{r} & -x_{3} \\
-\frac{L_{m}}{L_{r}} \omega_{r} & \frac{L_{m}}{L_{r}} \frac{r_{s}}{L_{s}} & -\omega_{r} & -x_{5} & -x_{4} \\
0 & 0 & 0 & 0 & 0
\end{array}\right]
\end{aligned}
$$

$$
z\left(t_{i}\right)=h\left[x\left(t_{i}\right), t_{i}\right]+v\left(t_{i}\right)
$$

where

$$
h\left[x\left(t_{i}\right), t_{i}\right]=\left[\begin{array}{c}
i_{q s f}\left(t_{i}\right) \\
i_{d s f}\left(t_{i}\right)
\end{array}\right]
$$

$$
\begin{aligned}
H & =\left.\frac{\partial \boldsymbol{h}[\boldsymbol{x}(t), u(t), t]}{\partial \boldsymbol{x}}\right|_{\boldsymbol{x}=\hat{\boldsymbol{x}}(t)} \\
& =\left[\begin{array}{lllll}
1 & 0 & 0 & 0 & 0 \\
0 & 1 & 0 & 0 & 0
\end{array}\right] .
\end{aligned}
$$




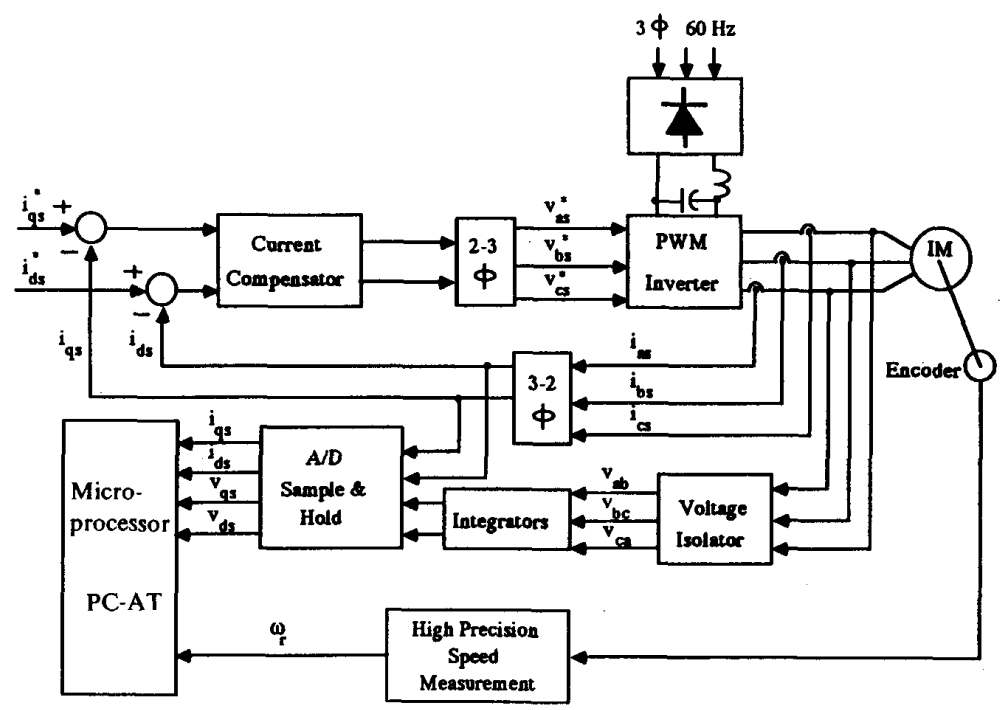

Fig. 3. On-line estimation of inverse rotor time constant of an induction machine.

\section{EXPERIMENTAL HaRdWARE AND RESUlts}

\section{System Hardware}

Both digital computer simulation and laboratory experiments were carried out to verify the feasibility of estimating the $r_{r} / L$, with the extended Kalman filter algorithm. The results from experiments agree with those from simulation. A general form of a current-regulated PWM drive with dataacquisition circuits and a microprocessor is shown in Fig. 3 . A proportional-plus-integral compensator is usually employed as the current compensator. It should be noted that the filter algorithm is independent of the inverter, CRPWM, or PWM. The filter only requires the stator voltages and currents and the rotor speed. In addition to a CRPWM drive, a PWM drive without current regulation was also used in the experiments. The motor under test is a 3-hp squirrel-cage induction motor.

The voltage isolator in Fig. 3 prevents damage to the data acquisition circuits and the microprocessor from the highvoltage drive. On-line data was collected by an IBM PC-AT with analog integrators and digital counters to measure the fundamental components of the PWM voltage waveforms and motor speed, respectively. Four-channel analog-to-digital converters are used to sample the outputs of the integrators and motor currents every $0.4 \mathrm{~ms}(2.5 \mathrm{kHz})$.

If only the lower triangular parts of symmetric matrices $\boldsymbol{P}$, $\boldsymbol{Q}$, and $\boldsymbol{R}$, defined in Appendix A, are computed, the total computation time for updating one estimation requires about 700 multiplications and 600 additions. For an Intel $80286 / 80287$ processor, which can execute 0.3 million floating-point instructions per second (0.3 MFLOPS), it takes about $4.5 \mathrm{~ms}$ to update the filter from $t_{i}$ to $t_{1+1}$. Since the sampling frequency is $2.5 \mathrm{kHz}$ and the total time record is $100 \mathrm{~ms}$, the total computation time is about $1125 \mathrm{~ms}(100 / 0.4$
$* 4.5 \mathrm{~ms}$ ). The updated estimate of $r_{r} / L_{r}$ is computed as

$$
\begin{aligned}
\frac{\hat{r}_{r}}{L_{r}}\left(t_{i}^{+}\right)= & \frac{\hat{r}_{r}}{L_{r}}\left(t_{i}^{-}\right)+k_{51}\left[i_{q s}\left(t_{i}\right)-\hat{i}_{q s}\left(t_{i}^{-}\right)\right] \\
& +k_{52}\left[i_{d s}\left(t_{i}\right)-\hat{i}_{d s}\left(t_{i}^{-}\right)\right] .
\end{aligned}
$$

A typical response of the Kalman gain $k_{51}$ and $k_{52}$ is illustrated in Fig. 4. $\hat{i}_{q s}\left(t_{i}^{-}\right)$and $\hat{i}_{d s}\left(t_{i}^{-}\right)$are generated by propagating the system dynamic equations in Appendix $\mathrm{A}$.

\section{Retrieval of Fundamental Component of PWM Voltage Waveform}

The measurement of the fundamental voltage components is essential to the accuracy of the parameter estimation. In the PWM inverter, the voltage waveforms are composed of high-frequency pulses, and this makes measurement of the motor terminal voltage difficult. Direct sampling the PWM waveform without a low-pass prefilter is out of the question due to the well-known aliasing problem; the typical sampling frequency of a microprocessor is less than $5 \mathrm{kHz}$. Conventional analog filters cannot be used as the prefilters devices because they cause phase shift and also tend to filter out the time-varying components of the original signals. Fortunately, in a $d-q$ reference system, the signal $v_{d s}$ leads $v_{q s}$ by $90^{\circ}$. An integrator is known to introduce a $90^{\circ}$ phase delay and to attenuate high-frequency signals. In this paper, integrators are used as the low-pass prefilter; however, this imposes a constraint on the stator frequency. Assume that the amplitude and frequency of the fundamental components vary according to the following equations:

$$
\begin{gathered}
v_{q s f}=V\left(1+k_{1} t\right) \sin \left(\left(\omega+k_{2} t\right) t\right) \\
v_{d s f}=V\left(1+k_{1} t\right) \cos \left(\left(\omega+k_{2} t\right) t\right) .
\end{gathered}
$$

From observing the derivative of (18), retrieval of the funda- 


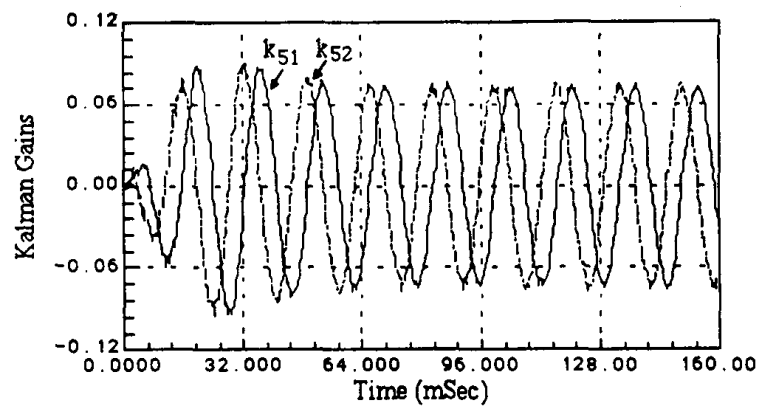

Fig. 4. Experimental data of the Kalman gains of an extended Kalman filter.

mental components with the integrators can be approximated as

$$
\begin{aligned}
v_{q s f}=\omega \int v_{d s} d t & +2 k_{2} \int t v_{d s} d t \\
& +k_{1} V \int \sin \left(\left(\omega+k_{2} t\right) t\right) d t \\
v_{d s f}=-\omega \int v_{q s} d t & -2 k_{2} \int t v_{q s} d t \\
& +k_{1} V \int \cos \left(\left(\omega+k_{2} t\right) t\right) d t
\end{aligned}
$$

where

$$
\begin{gathered}
v_{q s}=v_{q s f}+v_{q s h} \\
v_{d s}=v_{d s f}+v_{d s h} .
\end{gathered}
$$

$v_{q s h}\left(v_{d s h}\right)$ represents the sum of the high-frequency components, and $v_{q s f}\left(v_{d s f}\right)$ is the fundamental component of the PWM voltage waveform. If only the integrators (the first terms in 19) are used to retrieve the fundamental components of $v_{q s}$ and $v_{d s}$, the constants $k_{1}$ and $k_{2}$ related to time-varying components can introduce errors in both amplitude and phase of the approximated $v_{q s f}$ and $v_{d s f} ; k_{1}$ and $k_{2}$ are zeros in steady state.

In a short period of time, for the slowly time-varying terminal voltage, the fundamental components can be approximated as

$$
\begin{gathered}
v_{q s f} \simeq\left(p_{1 q}+p_{2 q} k_{2} t\right) \omega \int v_{d s} d t \\
v_{d s f} \simeq-\left(p_{1 d}+p_{2 d} k_{2} t\right) \omega \int v_{d s} d t .
\end{gathered}
$$

Equation (20) is quite accurate when $k_{1} t$ and $\frac{k_{2} t}{\omega}$ are less than 0.3 ; this places a constraint on the allowable variation of the stator frequency. $k_{2}$ can be estimated by the zero-crossing points of the $\int v_{q s} d t$ or $\int v_{d s} d t$, and $p_{1 q}, p_{2 q}, p_{1 d}$, and $p_{2 d}$ are computed off line by computer simulation.

The proposed method is to estimate the rotor time constant used in the indirect field-oriented control. Since the rotor time constant cannot dramatically change within a few $\mathrm{sec}-$ onds, the processor can constantly monitor the voltages and currents of the induction motor. Experiments suggested that the required sampling period is about $100 \mathrm{~ms}$. In high-speed servo applications, the estimation is updated only when the variation of the frequency within $100 \mathrm{~ms}$ meets the constraint of (20). The experimental results of the retrieved fundamental components are illustrated in Fig. 5. The smooth sinusoidal signals are the retrieved fundamental components.

\section{High-Precision Speed Measurement}

Speed measurement is critical to the accuracy of parameter estimation. A typical slip of an induction motor is about 0.04 . In this case, $1 \%$ error in the speed measurement can cause a large error in the indicated slip. This error can severely affect the accuracy of (10), which is used as an internal model in the Kalman filter algorithm. Conventional speed measurement is done by accumulating the pulses from an encoder within a fixed time period. With a high sampling rate $(2.5 \mathrm{kHz})$, the requirement on the encoder becomes unrealistically high, especially when the motor operates at low speed. An alternative to the speed measurement is to measure the time period of a certain number of encoder pulses with high-frequency pulses ( $2 \mathrm{MHz}$ ), as shown in Fig. 6 . Since the high-frequency pulses are generated by a highprecision crystal, the desired accuracy of the measurement can be achieved.

\section{On-Line Calculation of Magnetizing Inductance}

When the parameters used in the filter model deviate from the real machine parameters, the accuracy of the estimated $r_{r} / L_{r}$ is affected. Fortunately, from the experiments and computer simulation, only variations in the magnetizing inductance $L_{m}$ can cause a significant error in the estimate. The $L_{m}$ is difficult to determine while the motor is in normal operating conditions. Conventionally, a saturation curve and air-gap emf are used to find the $L_{m}$ through a look-up table. The air-gap emf is the motor terminal voltage minus the voltage drop across the stator resistance and leakage inductance. This method has some inherent inaccuracy because the magnetizing inductance is dominated by the magnetizing current $i_{m}$, but the air-gap emf is a function of both the $L_{m}$ and $i_{m}$. For instance, either a small $L_{m}$ and a large $i_{m}$ or a large $L_{m}$ and a small $i_{m}$ may produce the same air-gap emf.

An alternative for determining $L_{m}$ is to deal with the magnetizing current $i_{m}$ directly. A new $L_{m}$-versus- $i_{m}$ saturation curve can be constructed from the no-load test, shown in Fig. 7. The remaining problem is to find the $i_{m}$ in normal machine operations when the rotor current is no longer zero and is not perfectly known. Fig. 8 illustrates the phase angle $\theta_{s}$ between the stator voltage and current for a rated condition. The smooth sinusoidal signal is the retrieved fundamental component of the stator voltage. A phasor diagram representing the equivalent circuit of an induction motor is shown in Fig. 9. The phase angle $\theta_{s}$ can be used to calculate the $i_{m}$ with the following equations:

$$
\begin{gathered}
\tilde{E}=\tilde{V}-\tilde{I}_{s}\left(r_{s}+j X_{l s}\right) \\
\tilde{E}=\left[V-\left(I_{s} r_{s} \cos \theta_{s}+I_{s} X_{l s} \sin \theta_{s}\right)\right] \\
-j\left(I_{s} X_{l s} \cos \theta_{s}-I_{s} r_{s} \sin \theta_{s}\right) \\
\theta_{e}=\tan ^{-1} \frac{I_{s} X_{l s} \cos \theta_{s}-I_{s} r_{s} \sin \theta_{s}}{V-\left(I_{s} r_{s} \cos \theta_{s}+I_{s} X_{l s} \sin \theta_{s}\right)}
\end{gathered}
$$




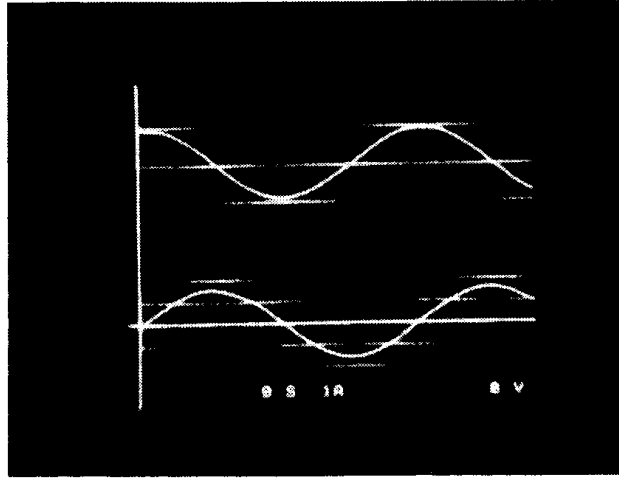

Fig. 5. Experimentally retrieved fundamental components of stator voltages.

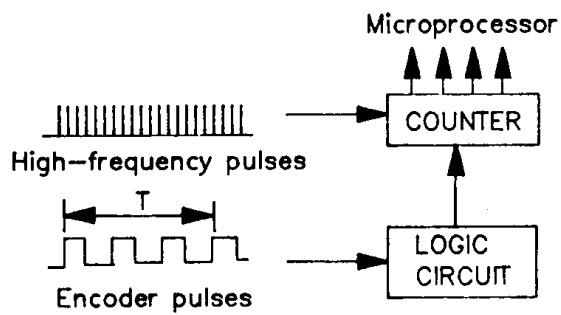

$N_{p}$ :number of encoder pulses within time period $T$. $\mathrm{N}_{\mathrm{c}}$ :number of pulses accumulated in counter.

$\mathrm{N}_{\mathrm{e}}$ :number of pulses per revolution.

$f_{c}$ : frequency of a high-precision crystal.

$$
\omega_{r}=\frac{\theta}{T} \quad \theta=2 \pi \frac{N_{p}}{N_{s}} \quad T=N_{c} \frac{1}{f_{c}}
$$

Fig. 6. High-precision speed measurement.

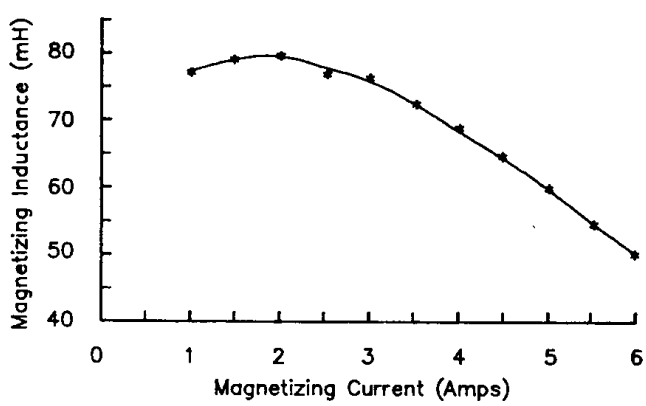

Fig. 7. Saturation curve of magnetizing inductance of a 3-hp induction machine.

$$
\begin{gathered}
\theta_{r}=\tan ^{-1} \frac{X_{l r}}{\left(r_{s} / s\right)} \\
\tilde{I}_{r}=\frac{\tilde{E}}{r_{r} / s+j X_{l r}} \\
I_{m}=I_{s} \sin \left(\theta_{s}-\theta_{e}\right)-I_{r} \sin \theta_{r}
\end{gathered}
$$

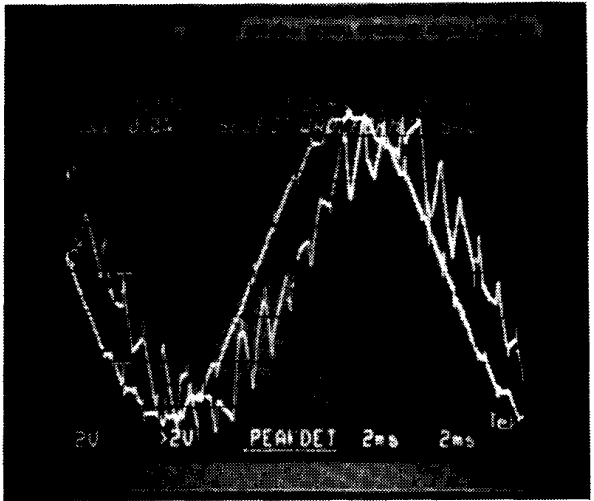

Fig. 8. Experimental stator voltage and current in a rated load condition.

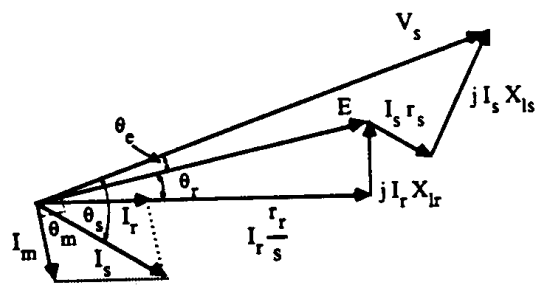

Fig. 9. Phasor diagram illustrating the computation of magnetizing current.

where

$$
\begin{gathered}
\tilde{V}=V \angle 0 \quad \tilde{E}=E \angle-\theta_{e} \\
\tilde{I}=I_{s}<-\theta_{s} \quad \tilde{I}_{r}=I_{r}<-\theta_{r} \\
\tilde{I}_{m}=I_{m}<-\theta_{m}
\end{gathered}
$$

and $s$ is the slip frequency of the induction motor. In the above equations, $X_{l s}, X_{l r}$, and $r_{r}$ are not exactly known. However, $\theta_{e}$ and $\theta_{r}$ are usually very small, and hence, the error caused by the parameter variations can be reduced. The $\theta_{s}$ can be computed by applying the fast Fourier transform (FFT) to the signals $v_{q s f}$ and $i_{q s}$. This proposed method is used to calculate the $L_{m}$ in Tables I and II, as shown in Appendix B.

\section{Experimental Results}

The experimental results for a PWM inverter, together with the simulation results, are summarized in Table $\mathbf{I}$, and the results of a CRPWM drive are listed in Table II. Driven by a temperature change, the stator resistance changes accordingly. The rotor resistance is then calculated as

$$
r_{r}\left(T_{2}\right)=r_{r}\left(T_{1}\right) \frac{r_{s}\left(T_{2}\right)}{r_{s}\left(T_{1}\right)} .
$$

$r_{r}\left(T_{1}\right)$ and $r_{s}\left(T_{1}\right)$ can be obtained from the manufacture's data. Current waveform of the PWM inverter is shown in Fig. 10. Fig. 11 illustrates the estimates of $r_{r} / L_{r}$ at two different temperatures. As expected, the estimated $r_{r} / L_{r}$ increases when motor becomes hot.

One experiment with a CRPWM drive was designed to 


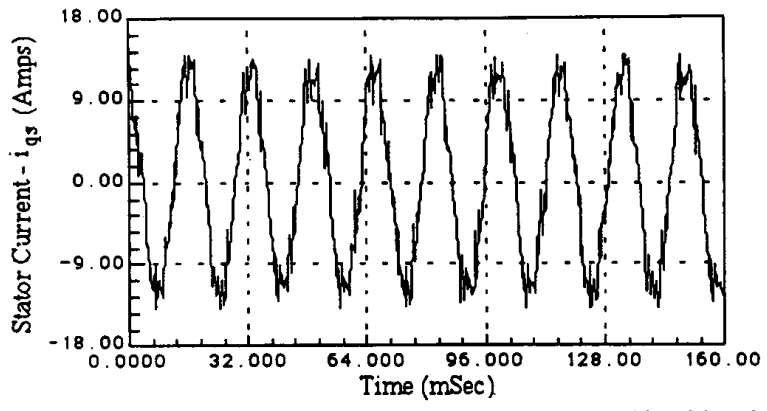

Fig. 10. Experimental stator current of a 3-hp induction machine driven by a PWM inverter.

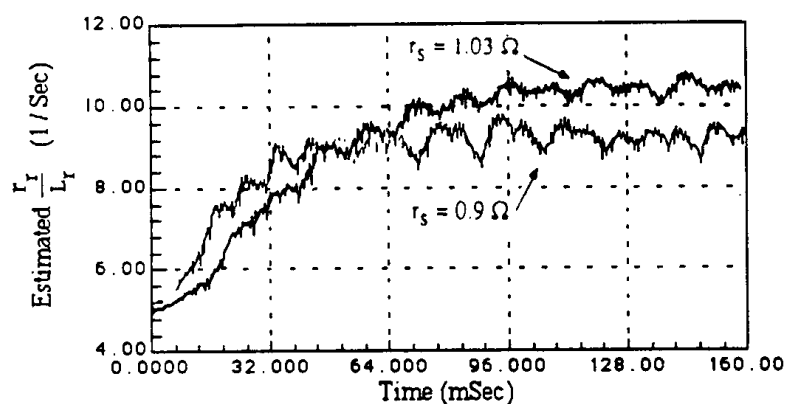

Fig. 11. Experimental estimates of inverse rotor time constant at two different temperatures.

examine the performance of the filter while the rotor speed was time varying. First, the motor was allowed to rotate at a constant speed of $500 \mathrm{r} / \mathrm{min}$; the motor current is shown in Fig. 12. Subsequently, a large load was applied to the rotor shaft. This load tended to stall the motor. The stator voltage shown in Fig. 13 decreased according to the decrease in the motor speed (see Fig. 14). Fig. 15 depicts the estimated $r_{r} / L_{r}$; this experiment demonstrates that the filter can still properly function while motor speed experiences significant variation. The experimental data listed in Tables I and II show the extended Kalman filter can effectively estimate the $r_{r} / L_{r}$ over a range from 1727 to $115 \mathrm{r} / \mathrm{min}$.

\section{Conclusions}

Induction motor drive systems with a field-oriented controller are presently considered as viable alternatives for replacing dc motor drives. However, changes in the rotor time constant have an important effect on the performance of the indirect field-oriented control drive systems. An on-line technique for estimating the rotor time constant of an induction motor without the use of additional sensors has been described. This technique was verified by computer simulation and tested on two different types of inverters (PWM and CRPWM). Both computer simulation and experimental data demonstrate that an extended Kalman filter can accurately estimate the inverse rotor time constant $r_{r} / L_{r}$ without disturbing the normal operations of the induction motor drive. This approach should be useful in various applications where rotor time constant changes can seriously deteriorate the performance of the drive.

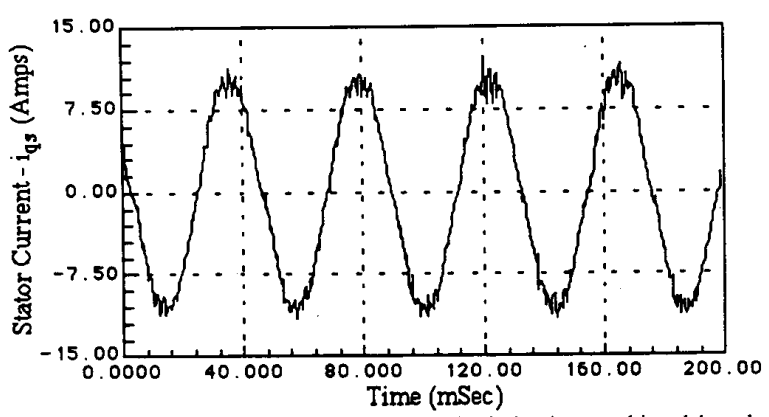

Fig. 12. Experimental stator current of a 3-hp induction machine driven by a CRPWM inverter.

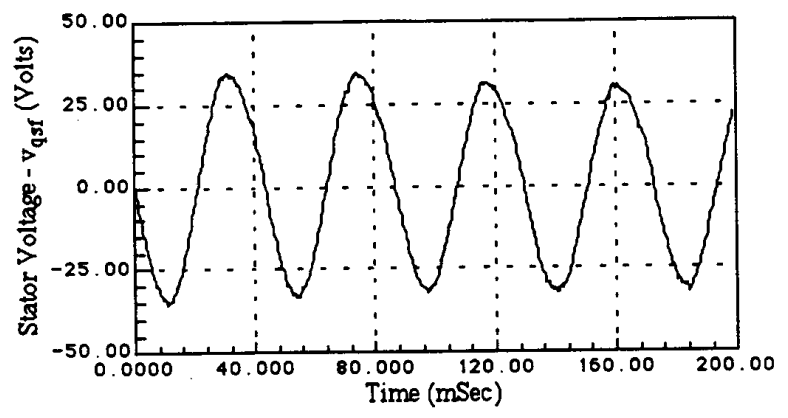

Fig. 13. Experimental stator voltage for time-varying rotor speed.

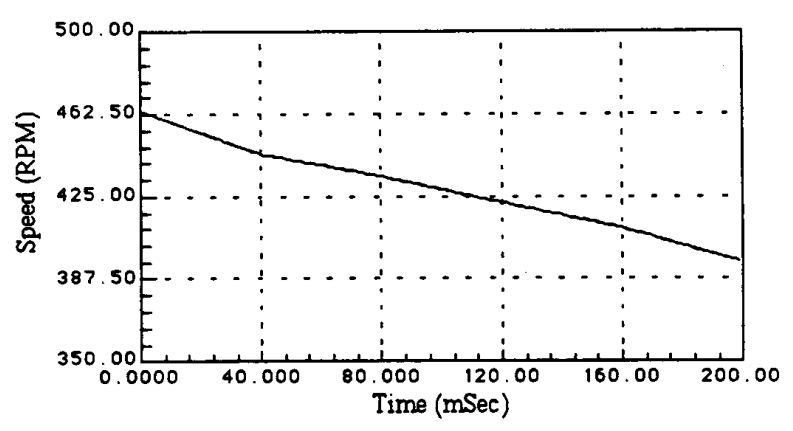

Fig. 14. Experimental data of time-varying rotor speed.

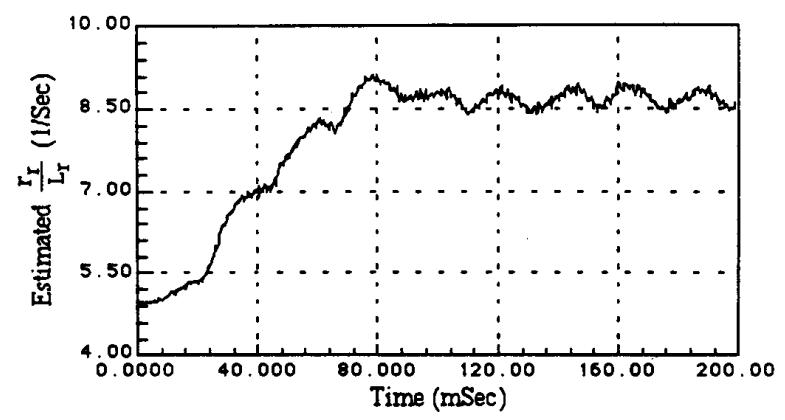

Fig. 15. Estimates of inverse rotor time constant in a time-varying condition. 


\section{APPENDIX A}

Extended Kalman Filter Algorithm [15]

The extended Kalman filter algorithm is described in the framework of the following equations, which are easily fit into the system models described in the body of this paper.

Models of system dynamics and discrete-time measurements:

$$
\begin{gathered}
\dot{x}(t)=f[x(t), u(t), t]+G w(t) \\
z\left(t_{i}\right)=h\left[x\left(t_{i}\right), t_{i}\right]+v\left(t_{i}\right) .
\end{gathered}
$$

Measurement update:

$$
\begin{gathered}
\boldsymbol{K}\left(t_{i}\right)=\boldsymbol{P}\left(t_{i}^{-}\right) \boldsymbol{H}^{r}\left[\hat{\boldsymbol{x}}\left(t_{i}^{-}\right), t_{i}\right]\left\{\boldsymbol{H P}\left(t_{i}\right) \boldsymbol{H}^{T}+\boldsymbol{R}\right\}^{-1} \\
\hat{\boldsymbol{x}}\left(t_{i}^{+}\right)=\hat{\boldsymbol{x}}\left(t_{i}^{-}\right)+\boldsymbol{K}\left(t_{i}\right)\left\{z\left(t_{i}\right)-\boldsymbol{h}\left[\hat{\boldsymbol{x}}\left(t_{i}\right), t_{i}\right]\right\} \\
\boldsymbol{P}\left(t_{i}^{+}\right)=\boldsymbol{P}\left(t_{i}^{-}\right)-\boldsymbol{K}\left(t_{i}\right) \boldsymbol{H P}\left(t_{i}^{-}\right) \\
\boldsymbol{H}[\boldsymbol{x}(t), t]=\left.\frac{\partial \boldsymbol{h}[\boldsymbol{x}(t), \boldsymbol{u}(t), t]}{\partial \boldsymbol{x}}\right|_{\boldsymbol{x}=\hat{\boldsymbol{x}}(t)} \\
\hat{\boldsymbol{x}}\left(t_{i+1}^{-}\right)=\hat{\boldsymbol{x}}\left(t_{i+1} / t_{i}\right) \\
\boldsymbol{P}\left(t_{i+1}^{-}\right)=\boldsymbol{P}\left(t_{i+1} / t_{i}\right) .
\end{gathered}
$$

Propagation of system dynamic equations and covariance matrix $P(t)$ :

$$
\begin{gathered}
\dot{\hat{x}}\left(t / t_{i}\right)=f\left[x\left(t / t_{i}\right), u(t), t\right] \\
\dot{\boldsymbol{P}}\left(t / t_{i}\right)=\boldsymbol{F}\left[\hat{\boldsymbol{x}}\left(t / t_{i}\right), t\right] \boldsymbol{P}\left(t / t_{i}\right) \\
+\boldsymbol{P}\left(t / t_{i}\right) \boldsymbol{F}^{T}\left[\hat{\boldsymbol{x}}\left(t / t_{i}\right), t\right]+G Q \boldsymbol{G}^{T} \\
\boldsymbol{F}[\boldsymbol{x}(t), t]=\left.\frac{\partial f[\boldsymbol{x}(t), u(t), t]}{\partial \boldsymbol{x}}\right|_{x=\hat{x}(t)} \\
\hat{\boldsymbol{x}}\left(t_{i} / t_{i}\right)=\hat{\boldsymbol{x}}\left(t_{i}^{+}\right) \\
\boldsymbol{P}\left(t_{i} / t_{i}\right)=\boldsymbol{P}\left(t_{i}^{+}\right) .
\end{gathered}
$$

\section{APPENDIX B}

TABLES OF EXPERIMENTAL RESUlts

\footnotetext{
SIM data from computer simulation

** data obtained from extended Kalman filter algorithm $r_{s}^{*} \quad$ measured with a Kelvin bridge

$r_{r}^{*} \quad$ computed with $(22)$ and $r_{s}^{*}$

$L_{m}^{*} \quad$ obtained with (21) and Fig. 7

$L_{r}^{*}=L_{m}^{*}+L_{l r}$

$\frac{r_{r}^{*}}{L_{r}}=\frac{r_{r}^{*}}{L_{r}^{*}}$
}

TABLE I

Allen-Bradley (AB) PWM Inverter

\begin{tabular}{lcccccc}
\hline \multicolumn{1}{c}{ Drive } & AB & AB & AB & AB & SIM & SIM \\
\hline$f_{e}(\mathrm{hz})$ & 60.0 & 60.0 & 7.70 & 8.80 & 60.0 & 60.0 \\
$\omega_{r}(\mathrm{rpm})$ & 1727 & 1727 & 115 & 114 & 1727 & 1727 \\
slip & 0.0406 & 0.0406 & 0.502 & 0.568 & 0.0406 & 0.0406 \\
Voltage $(\mathrm{rms})$ & 122.8 & 127.8 & 14.89 & 17.15 & 102.6 & 109.5 \\
Current (rms) & 8.72 & 8.15 & 7.71 & 8.00 & 6.98 & 7.00 \\
$r_{s}^{*}(\mathrm{ohm})$ & 0.90 & 1.03 & 0.90 & 1.03 & 0.90 & 1.03 \\
$r_{r}^{*}(\mathrm{ohm})$ & 0.586 & 0.670 & 0.586 & 0.670 & 0.586 & 0.670 \\
$L_{m}^{*}(\mathrm{mh})$ & 65 & 65 & 78 & 78 & 65 & 65 \\
$L_{r}^{*}(\mathrm{mh})$ & 66.8 & 66.8 & 79.8 & 79.8 & 66.8 & 66.8 \\
$r_{r} / L_{r}^{*}\left(s^{-1}\right)$ & 8.77 & 10.03 & 7.34 & 8.40 & 8.77 & 10.03 \\
$r_{r} / L_{r}^{* *}\left(s^{-1}\right)$ & 9.2 & 10.4 & 8.1 & 9.1 & 8.2 & 9.4 \\
$\%$ Change* & \multicolumn{2}{c}{+14.37} & +14.44 & & +14.37 \\
$\%$ Change & & +13.0 & & +12.4 & & +14.6 \\
\hline
\end{tabular}

TABLE II

UNIVERSITY OF WISCONSIN (UW) CRPWM INVERTER

\begin{tabular}{lccccc}
\hline \multicolumn{1}{c}{ Drive } & $\mathrm{UW}$ & $\mathrm{UW}$ & $\mathrm{UW}$ & $\mathrm{UW}$ & $\mathrm{UW}$ \\
\hline$f_{e}(\mathrm{hz})$ & 23.54 & 23.54 & 6.10 & 6.10 & 23.18 \\
$\omega_{r}(\mathrm{rpm})$ & 658 & 643 & 121 & 132 & $395-462$ \\
slip & 0.0683 & 0.0895 & 0.339 & 0.279 & \\
Voltage (rms) & 63.17 & 64.30 & 16.83 & 18.95 & \\
Current (rms) & 7.52 & 7.47 & 7.59 & 7.61 & 7.25 \\
$r_{s}^{*}(\mathrm{ohm})$ & 0.94 & 1.06 & 0.94 & 1.05 & 0.94 \\
$r_{r}^{*}(\mathrm{ohm})$ & 0.61 & 0.69 & 0.61 & 0.68 & 0.61 \\
$L_{m}^{*}(\mathrm{mh})$ & 65 & 65 & 62 & 62 & 75 \\
$L_{r}^{*}(\mathrm{mh})$ & 66.8 & 66.8 & 63.8 & 63.8 & 76.8 \\
$r_{r} / L_{r}^{*}\left(s^{-1}\right)$ & 9.16 & 10.33 & 9.59 & 10.71 & 7.97 \\
$r_{r} / L_{r}^{* *}\left(s^{-1}\right)$ & 8.9 & 10.4 & 8.9 & 9.8 & 8.8 \\
$\%$ Change & \multicolumn{5}{c}{+12.77} \\
$\%$ Change $^{* *}$ & +16.9 & \multicolumn{7}{c}{+11.70} & \\
\hline
\end{tabular}

\section{REFERENCES}

[1] K. Hasse, "Zur Dynamik drehzahlgeregelter Antriebe mit stromrichtergespeisten Asynchron-kurzschlußläufermaschinen," Dissertation, TH Darmstadt, 1969.

[2] F. Blaschke, "Das Prinzip der Feldorientierung, die Grundlage für die TRANSVEKTOR-Regelung von Asynchronmaschinen," Siemens-Zeitschrift, vol. 45, p. 757, 1971.

[3] M. Koyama and H. Sugimoto, "Effects on parameter change on coordinate control system of induction motor," in Proc. IPEC (Tokyo), 1983, pp. 684-695.

[4] K. B. Nordin, D. W. Novotny, and D. S. Zinger, "The influence of motor parameter deviations in feedforward field orientation drive systems," in Proc. IEEE-IAS Ann. Mtg. Conf. Rec., Sept. 30-Oct. 4, 1984, pp. 525-531.

[5] L. J. Garce, "Parameter adaptation for the speed-controlled static ac drive with a squirrel-cage induction motor," IEEE Trans. Industry Applications, vol. IA-16, no. 2, pp. 173-178, 1980.

[6] T. Irisa, S. Takata, R. Ueda, and T. Sonada, "On reliability of induction machine for high performance based on parameter characteristics," in Proc. IEEE-IAS Ann. Mtg. Conf. Rec., Oct. 3-7, 1983 , pp. $547-554$.

[7] H. Kubota, K. Matsuse, and T. Fukao, "New control method of inverter-fed induction motor drive by using state observer with rotor resistance identification," Elect. Eng. Japan, vol. 105, no. 5, pp. $119-127,1985$.

[8] H. Sugimoto and S. Tamai, "Secondary resistance identification of an induction motor: Applied model reference adaptive system and its characteristics," in Proc. IEEE-IAS Ann. Mtg. Conf. Rec., Oct. 6-11, 1985, pp. 613-620.

[9] R. Gabriel and W. Leonhard, "Microprocessor control of induction motor," in Proc. IEEE-IAS Int. Semiconductor Power Conv. Conf., May 24-27, 1982, pp. 385-396.

[10] T. Matsuo and T. A. Lipo, "A rotor parameter identification scheme for vector controlled induction motor drives," in Proc. IEEE-IAS Ann. Mtg. Conf. Rec., Sept. 30-Oct. 4, 1984, pp. 538-545.

[11] T. Okuyama, H. Nagase, and Y. Kubota, "High performance ac motor speed control system using GTO converters," in Proc. IPEC (Tokyo), 1983, pp. 720-730. 
[12] W. Leonhard, Control of Electrical Drives. Berlin: SpringerVerlag, 1985.

[13] Y. Dote and K. Anbo, "Combined parameter and state estimation of controlled current induction motor drive system via stochastic nonlinear filtering technique," in Proc. IEEE-IAS Ann. Mtg. Conf. Rec., 1979, pp. 838-842.

[14] F. Hillenbrand, "A method for determining the speed and rotor flux of the asynchronous machine by measuring the terminal quantities," in Proc. 3rd IFAC Symp. Contr. Power Electron. Elec. Drives, Sept. 1983, pp. 55-62.

[15] P. S. Maybeck, Stochastic Models, Estimation and Control. New York: Academic, 1982, vols. 1 and 2.

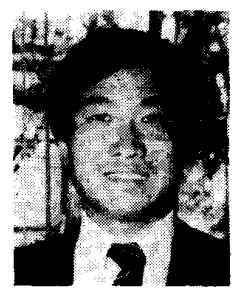

Li-Cheng Zai (S'85-M'88) received the B.S. degree from National Taiwan University in 1980 and the M.S. and Ph.D. degrees from the University of Wisconsin-Madison in 1984 and 1987, respectively.

Since 1987, he has been a research staff member at IBM Research Division, Yorktown Heights, NY. His current research interests include design of a high-performance digital controller, real-time control of high-speed electromechanical devices, digi tal signal processing, robotics, and power electronics.

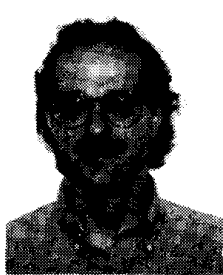

Christopher L. DeMarco (S'80-M'85) was born in Derby, CT, in 1958. He received the Bachelor of Science degree from Massachusetts Institute of Technology, Cambridge, in June of 1980 and the Ph.D. degree in electrical engineering and computer sciences from the University of California, Berkeley in May 1985.

In January 1985, he joined the faculty of the Department of Electrical and Computer Engineering at the University of Wisconsin-Madison, where he is currently an Associate Professor.

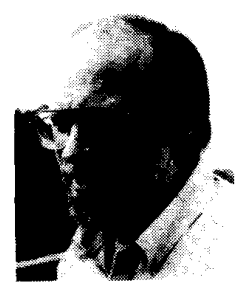

Thomas A. Lipo (M'64-SM'71-F'87) received the B.E.E. and M.S.E.E. degrees from Marquette University, Milwaukee, WI, in 1962 and 1964, respectively, and the $\mathrm{Ph} . \mathrm{D}$. degree in electrical engineering from the University of Wisconsin in 1968. He was an NRC Postdoctoral Fellow at the University of Manchester Institute of Science and Technology, Manchester, England, from 1968 to 1969.

From 1969 to 1979 , he was an Electrical Engineer in the Power Electronics Laboratory of Corporate Research and Development of the General Electric Company, Schenectady, NY. He became Professor of Electrical Engineering at Purdue University, Lafayette, IN, in 1979 and later joined the University of Wisconsin, Madison, in the same capacity. He has been involved in the research of power electronics and ac drives for over 25 years.

Dr. Lipo has received 11 IEEE prize paper awards including corecipient of the Best Paper Award in IEEE Transactions on Industry Applications for 1984. In 1986, he received the Outstanding Achievement Award from the IEEE Industry Applications Society for his contributions to the field of ac drives. 